\title{
DOE/OA/00033-T776
}

\section{LABOR MARKET TRENDS FOR NUCLEAR ENGINEERS THROUGH 2005}

\section{RECEIVED \\ SEP 301997 \\ OSTI}

October 1996

Prepared by:

Analysis and Evaluation Programs

Oak Ridge Institute for Science and Education

Prepared for:

U.S. Department of Energy

and

Office of Personnel

U.S. Nuclear Regulatory Commission 


\section{DISCLAIMER}

This report was prepared as an account of work sponsored by an agency of the United States Government. Neither the United States Government nor any agency thereof, nor any of their employees, makes any warranty, express or implied, or assumes any legal liability or responsibility for the accuracy, completeness, or usefulness of any information, apparatus, product, or process disclosed, or represents that its use would not infringe privately owned rights. Reference herein to any specific commercial product, process, or service by trade name, trademark, manufacturer, or otherwise does not necessarily constitute or imply its endorsement, recommendation, or favoring by the United States Government or any agency thereof. The views and opinions of authors expressed herein do not necessarily state or reflect those of the United States Government or any agency thereof. 


\title{
DOE/OR/00033-T776
}

\section{LABOR MARKET TRENDS FOR NUCLEAR ENGINEERS THROUGH 2005}

\author{
Prepared by: \\ Norman Seltzer \\ Larry M. Blair \\ Analysis and Evaluation Programs \\ Oak Ridge Institute for Science and Education
}

Prepared for:

U.S. Department of Energy

and

Office of Personnel

U.S. Nuclear Regulatory Commission

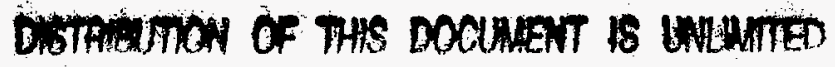

October 1996

\section{MASTER}

This paper is based on work conducted by the Oak Ridge Institute for Science and Education for the U.S. Nuclear Regulatory Commission and the U.S. Department of Energy under contract No. DE-AC05-760R00033.

All opinions expressed in this paper are the authors' and do not necessarily reflect policies and views of the U.S. Nuclear Regulatory Commission, the U.S. Department of Energy, or the Oak Ridge Institute for Science and Education. 


\section{TABLE OF CONTENTS}

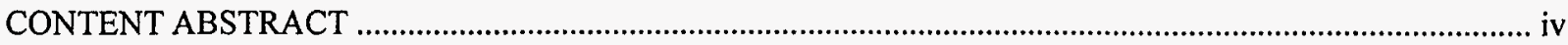

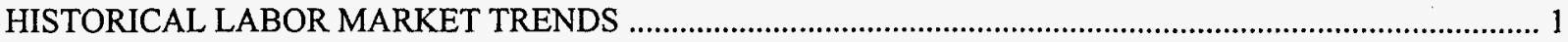

Overview: Trends in Degrees and Employment, 1983-1995 ....................................................................... 1

Estimating Job Openings for New Graduates ................................................................................................ 2

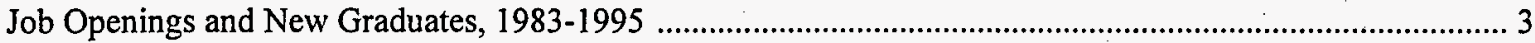

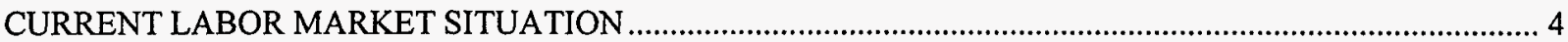

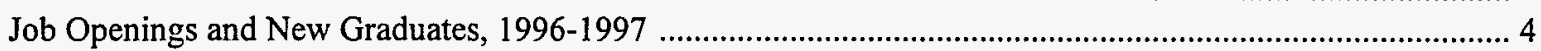

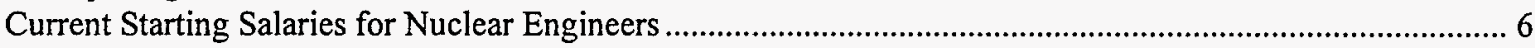

LABOR MARKET OUTLOOK FOR NEW GRADUATES, 1998-2000 ….................................................... 7

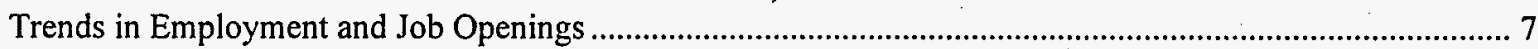

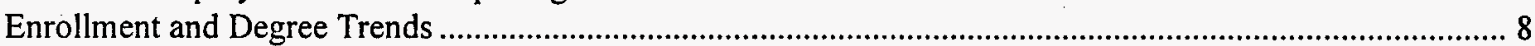

Job Openings and Available Supply Outlook ............................................................................................ 8

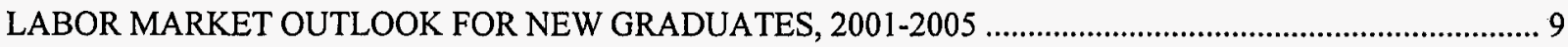

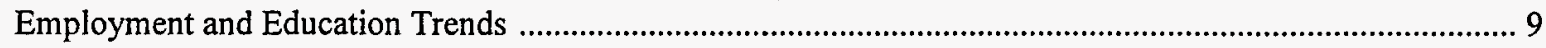

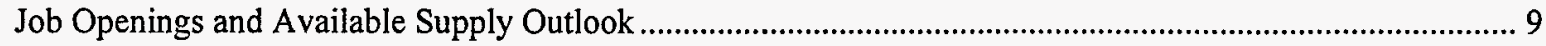

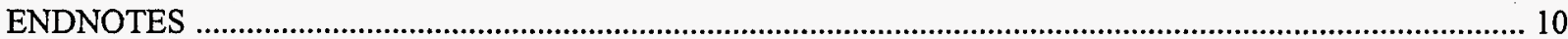




\section{LIST OF FIGURES}

1. Employment of Nuclear Engineers in the Nuclear Energy Field ............................................................ 1

2. Total Number Nuclear Engineering Degrees and Number of New Graduates Available for

U.S. Civilian Employment ............................................................................................................................. 2

3. Available Supply of New Graduates per 100 Job Openings for New Graduates in the

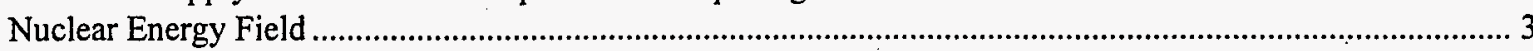

4. Estimated Employment Trends for Nuclear Engineers in the Nuclear Energy Field .......................................5

5. Estimated Available Supply of New Graduates per 100 Job Openings for New Graduates in the

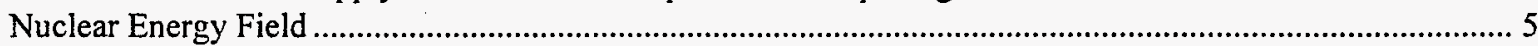

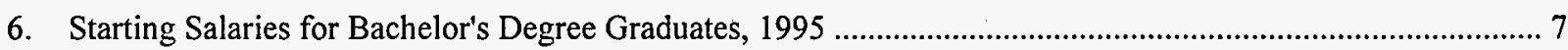

\section{LIST OF TABLES}

Table 1. Employment of Nuclear Engineers by Nuclear Energy Segment, 1993 and 1995 


\section{CONTENT ABSTRACT}

\section{HISTORICAL TRENDS}

Between 1983 and 1989, employment of nuclear engineers in the nuclear energy field* increased almost 40 percent while the annual number of nuclear engineering degrees awarded decreased by almost one-fourth. There were, on average, more job openings for new graduates than there were new graduates available to fill the jobs during the 1980 s.

This trend reversed in the 1990s as nuclear engineering employment in the nuclear energy field decreased from 11,500 in 1991 to 9,400 in 1995 . During roughly the same period, the annual number of nuclear engineering degrees increased by 11 percent. As a result, from 1990 through 1995, the number of new graduate nuclear engineers available in the labor supply far exceeded the number of job openings for new graduates in the nuclear energy field. This oversupply of new graduates was particularly acute for 1993 through 1995 . The oversupply did not result in high unemployment rates for new graduates as relatively more of them continued study (often in a different discipline), entered the military, found nuclear engineering positions outside of the nuclear energy field, or obtained employment in nonnuclear engineering occupations (both within and outside of the nuclear energy field).

\section{CURRENT TRENDS}

During 1996-1997, a relative improvement is expected in job opportunities in the nuclear energy field for new graduates; however, a large oversupply is still expected (almost twice as many graduates available for employment as there are job openings). Based on discussions with faculty in 20 nuclear engineering programs, nuclear engineering graduates are continuing to obtain employment outside of the nuclear energy field and in nonnuclear engineering fields.

\section{FUTURE TRENDS}

For 1998 through 2000, some improvement is expected in the relative number of job opportunities for new graduates in the nuclear energy field. Nuclear engineering jobs in the nuclear energy field are expected to decrease only slightly (by less than 150) during this period. Also, a 10 to 15 percent decrease in the annual number of degrees and available supply of new graduates is expected (based on the reduction in enrollments that has occurred over the past 3 years). Overall, an oversupply is expected ( 140 graduates available per 100 job openings for new graduates in the nuclear energy field), but this is still a substantial improvement over the current period. For 2001 through 2005, if enrollments and degrees continue to decline, the labor market for new graduates is expected to be approximately balanced. This assumes, however, that the number of degrees and the available supply of new graduates will decrease by 25 percent from 1995 levels.

\footnotetext{
* The nuclear energy field includes nuclear electric power operation, maintenance and scrvicing, vendors, the fuel cycle, decontamination and decommissioning, waste management and environmental restoration, research, government, university faculty, and nuclear defense activities. Excluded are medical facilities and active duty military.
} 


\section{HISTORICAL LABOR MARKET TRENDS}

\section{Overview: Trends in Degrees and Employment, 1983-1995}

From 1983 to 1991, employment of nuclear engineers in the nuclear energy field increased by 19 percent to a high of 11,500 in $1991 .^{1}$ Employment then decreased sharply by 16 percent to a level of 9,400 in $1995 .^{2}$ (Figure 1.) While nuclear engineers are employed in a wide variety of nuclear energy-related activities, 75 percent of the employment is concentrated in three segments - government; reactor operation and maintenance; and reactor/ facility design, manufacture, and redesign/betterment/backfit (RBB). Employment of nuclear engineers declined between 1993 and 1995 in every nuclear segment except waste management and decommissioning/ decontamination. By far, the largest decrease (44 percent) was in reactor/facility design, manufacture, and redesign/ betterment/backfit. (Table 1.)

FIGURE 1. EMPLOYMENT OF NUCLEAR ENGINEERS IN THE NUCLEAR ENERGY FIELD

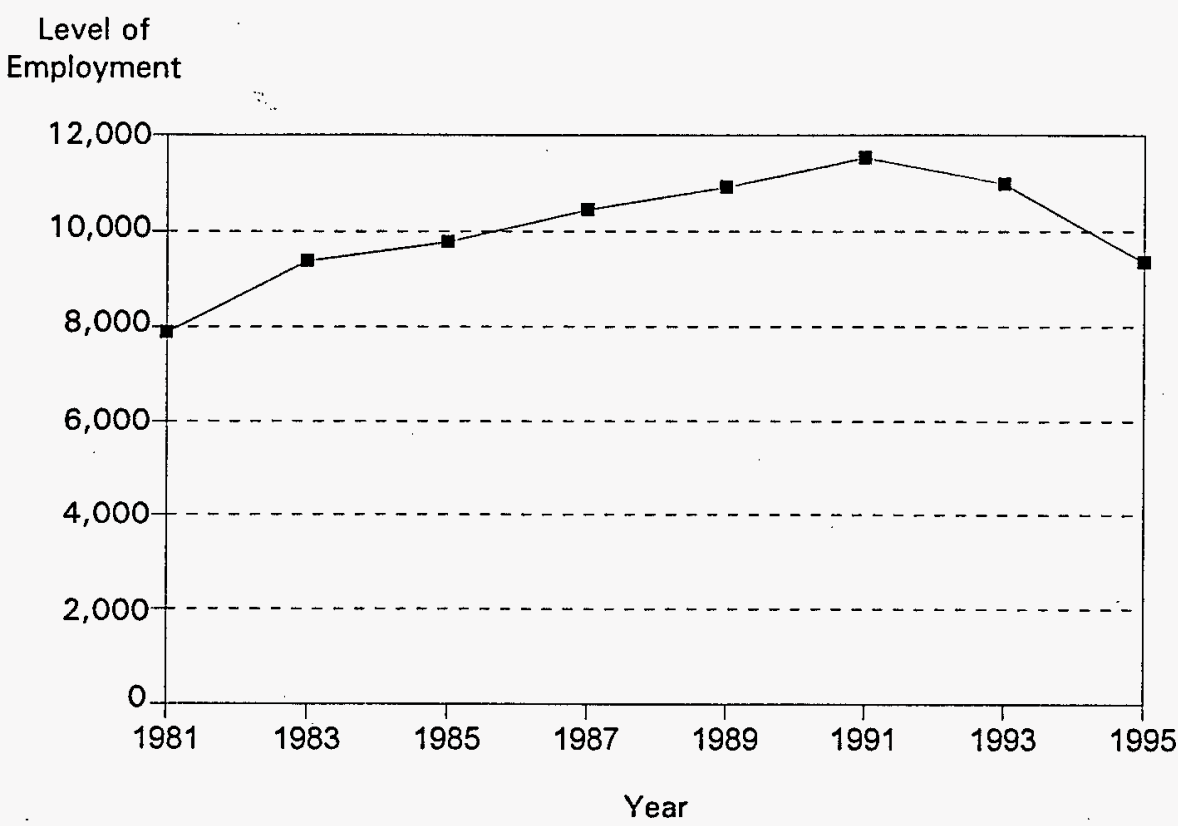

TABLE 1. EMPLOYMENT OF NUCLEAR ENGINEERS BY NUCLEAR ENERGY SEGMENT, 1993 AND 1995

Nuclear Energy Segment *

\begin{tabular}{rr}
1993 & 1995 \\
\hline 2,610 & 2,470 \\
2,070 & 1,160 \\
110 & 40 \\
370 & 580 \\
780 & 670 \\
500 & 300 \\
370 & 340 \\
3,660 & 3,450 \\
630 & 390 \\
11,100 & 9,400
\end{tabular}

Reactor Operation and Maintenance

Reactor, Facility, \& Instrument Design \& Manufacture and RBB

Fuel Cycle

Waste Management, Decommissioning, and Decontamination

Non-University Research and Development

University Faculty and Staff

Weapons Development

Government

Miscellaneous

11,100

9,400

"Employment for organizations reporting the segment as the primary activity in which that organization was engaged during the survey year. 
The total number of degrees (bachelor's plus master's plus doctorates) decreased continuously from 1984 through 1992 (from 1,100 to 730 degrees, a 34 percent decline). The number of degrees then steadily increased by 11 percent between 1992 and 1995, totaling 812 degrees in $1995 .{ }^{3}$ The trend in the annual number of nuclear engineering degrees and the trend in the estimated supply of new graduates available for U.S. civilian employment positions are shown in Figure $2 .{ }^{4}$

\section{FIGURE 2. TOTAL NUMBER NUCLEAR ENGINEERING DEGREES AND NUMBER OF NEW GRADUATES AVAILABLE FOR U.S. CIVILIAN EMPLOYMENT}

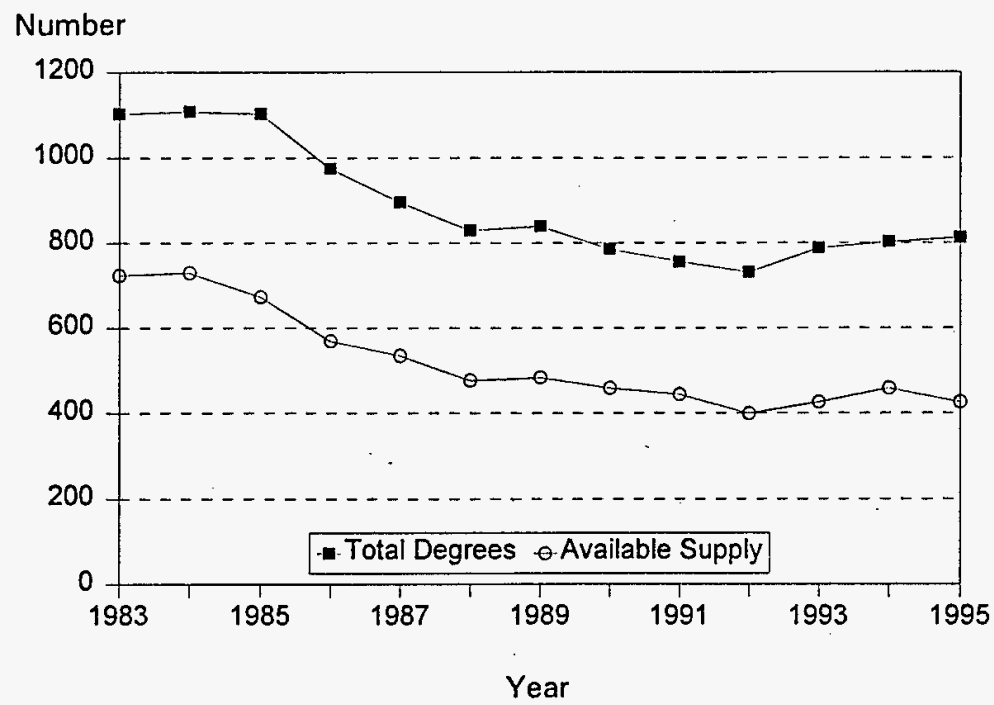

\section{Estimating Job Openings for New Graduates}

Job openings occur for two reasons: (1) growth in employment, and (2) replacement needs for nuclear engineers who vacate their employment positions because of retirement, leaving the labor force, death, or switching to a different occupation (such as other engineering fields, management, sales). While some of the nuclear engineering job openings are filled by persons returning to nuclear engineering positions or by workers moving in from other engineering or science fields, most job openings are filled by new graduates.

Actual labor force movements are complex, and detailed data on occupational mobility and job openings do not exist; however, net job openings for new graduates (the number of replacement and new positions to be filled by new graduates) can be estimated using data and methods developed by the Bureau of Labor Statistics as adjusted by the Oak Ridge Institute for Science and Education. 5 Estimates for attrition of nuclear engineers through 1995 are based on a 4.0 percent annual net attrition rate. Estimates of current and future attrition are based on a 3.5 percent annual net attrition rate reflecting a somewhat younger age distribution for nuclear engineers than in the past.

Because the job openings for new graduates are estimates based on employment trends and historical average annual attrition data (adjusted for age distributions), the actual number of job openings in the nuclear energy field 
for new graduates during any single year may be somewhat lower or higher than the estimates provided in this report. In addition, the overall number of job opportunities for the new nuclear engineering graduates depends not only on the labor market within the nuclear energy field but also on the supply and demand conditions in the broader labor market. New nuclear engineering graduates have job opportunities (1) as nuclear engineers in nonnuclear energy fields, and (2) in nonnuclear engineering occupations for which they are qualified. ${ }^{6}$ The number of job opportunities outside of nuclear engineering depends on the qualifications of the nuclear engineering graduates in comparison to other job seekers.

\section{Job Openings and New Graduates, 1983-1995}

For the total period of 1983-1995, estimated job openings in the nuclear energy field for new graduates averaged approximately 450 positions annually while the average annual number of graduates available for U.S. civilian employment was approximately 500. Thus, on average, during 1983 through 1995 there were approximately 110 graduates available per 100 job openings. However, there was a significant difference in the supply of available graduates to job openings between the 1980s and the first half of the 1990s.

For 1983-1989, the average was approximately 90 available graduates per 100 job openings, but this increased substantially to an average of approximately 350 available graduates per 100 job openings during 1990-1995.

(Figure 3.) The 1990-1995 period began with a fairly balanced labor market, but an oversupply of new graduates began to occur in 1992, which became a very large oversupply of new graduates for 1993 through 1995 . Thus, the data indicate an inadequacy of supply of new graduates during the 1980s, changing to a considerable oversupply in the first half of the 1990s. This drastic change resulted primarily from the sharp decline in employment beginning after 1991 which accelerated between 1993 and 1995, and secondarily from the increase in the annual number of degrees since 1992 .

\section{FIGURE 3. AVAILABLE SUPPLY OF NEW GRADUATES PER 100 JOB OPENINGS FOR NEW GRADUATES IN THE NUCLEAR ENERGY FIELD \\ (Annual Averages Within the Time Period)}

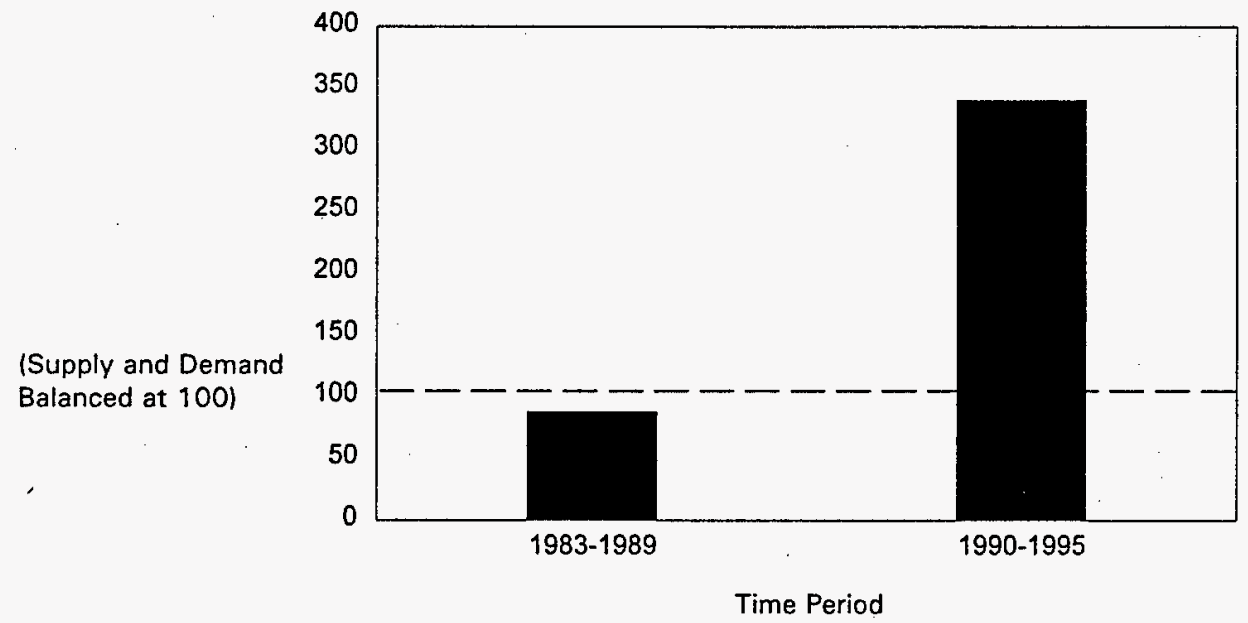


Data from recent National Science Foundation surveys of scientists and engineers, the College Placement Council, the nuclear engineering enrollment and degree surveys conducted for the U.S. Department of Energy by the Oak Ridge Institute for Science and Education, and information obtained in discussions with nuclear engineering departments confirm the oversupply of new graduates during 1990 through 1995 . Fewer graduates obtained nuclear engineering jobs in the nuclear energy field, there was less recruiting on campus, and graduates had to search longer to obtain jobs. Also, relatively more graduates went on to graduate school; more obtained positions as nuclear engineers outside of the nuclear energy field; more entered the military; and an increasing number of graduates obtained nonnuclear engineering jobs such as mechanical engineers, computer scientists or engineers, and, to a lesser extent, as radiation protection specialists and materials researchers. Many of the graduates finding employment with electric utilities were working in nonnuclear engineering positions.

Data from the 1993 National Science Foundation (NSF) surveys of scientists and engineers indicate that 88 percent of the 1990 nuclear engineering graduates held jobs as nuclear engineers compared to 77 percent for 1991 graduates, 40 percent for 1992 graduates, and less than 25 percent for 1993 graduates. ${ }^{7}$ Although these data are based on a relatively small sample of graduates, the downward trend is obvious.

Another indicator of the lessening opportunities for nuclear engineering employment is the experience of the American Nuclear Society's (ANS) employment placement activities at their national meetings. In 1994 and 1995, over 200 applicants submitted job resumes while only 11 companies in 1994 and 6 or 7 companies in 1995 were recruiting. Furthermore, some of the employers did not appear to be actively recruiting but rather appeared to be building inventories of qualified applicants. As a result, in 1996, the ANS eliminated the job placement activities at the meetings since many of the applicants indicated that this activity was nonproductive.

Data collected by Institute of Nuclear Power Operations (INPO) in its January 1995 biennial survey of employment in nuclear electric utilities indicated that 3.1 percent of the nuclear and reactor engineering positions were vacant, a slightly lower percentage than existed two years earlier and substantially lower than in 1991 . However, the 1994 turnover rate for nuclear and reactor engineers leaving electric utility employment was 3.7 percent, a higher rate than reported for two years earlier.

The ability of nuclear engineering graduates to secure employment in other occupations has maintained employment opportunities for new graduates, and thus the oversupply has not led to high unemployment rates among new graduates. In addition, based on the 1993 NSF survey data, the graduates taking positions outside the nuclear energy field (either as nuclear engineers or in other occupations) had salaries, on average, that were approximately the same as the salaries earned by graduates obtaining employment in the nuclear energy field. ${ }^{8}$

\section{CURRENT LABOR MARKET SITUATION}

\section{Job Openings and New Graduates, 1996-1997}

Estimates of current employment trends for nuclear engineers in the nuclear energy field indicate a modest decline of about 300 employment positions between 1995 and 1997. (Figure 4.) This is substantially less than the decreases experienced from 1991 to 1995 and especially from 1993 to 1995. Most of the decline is anticipated to 


\section{FIGURE 4. ESTIMATED EMPLOYMENT TRENDS FOR NUCLEAR ENGINEERS IN THE NUCLEAR ENERGY FIELD}

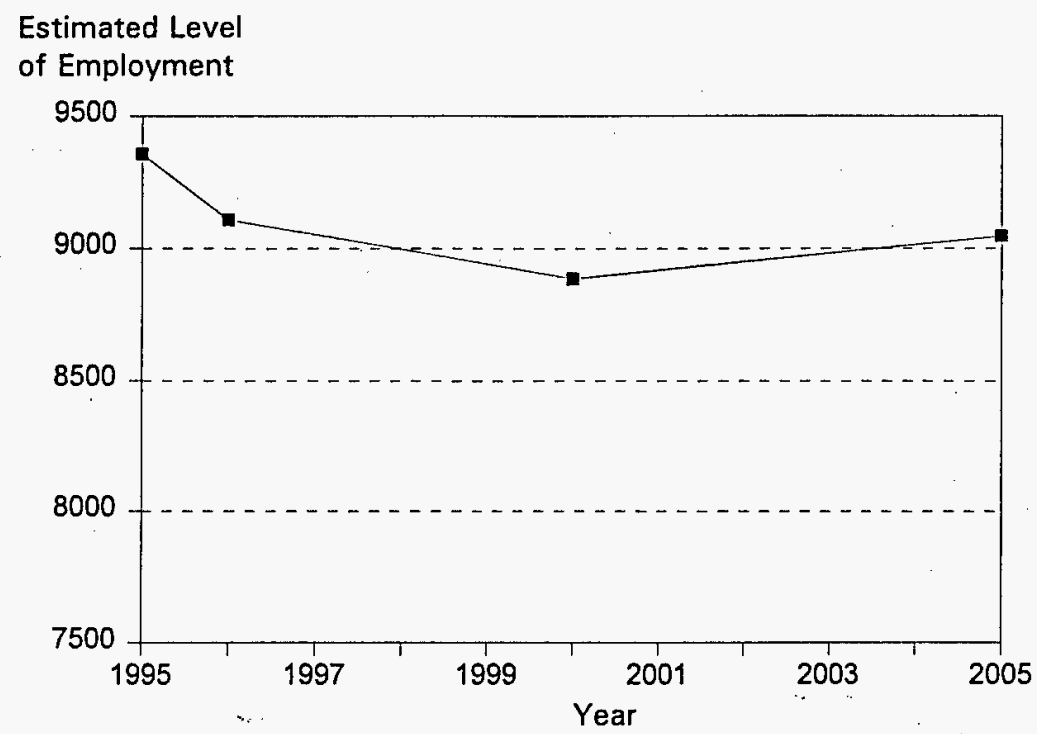

occur in Department of Energy-funded activities, particularly in government, research and development, and waste management and environmental restoration. During 1996 through 1997, the ratio of the estimated number of the available new graduates to job openings still indicates a considerable oversupply of new graduates: approximately 200 available graduates per 100 job openings. (Figure 5.)

\section{FIGURE 5. ESTIMATED AVAILABLE SUPPLY OF NEW GRADUATES* PER 100 JOB OPENINGS FOR NEW GRADUATES IN THE NUCLEAR ENERGY FIELD \\ (Annual Averages Within the Time Periods)}

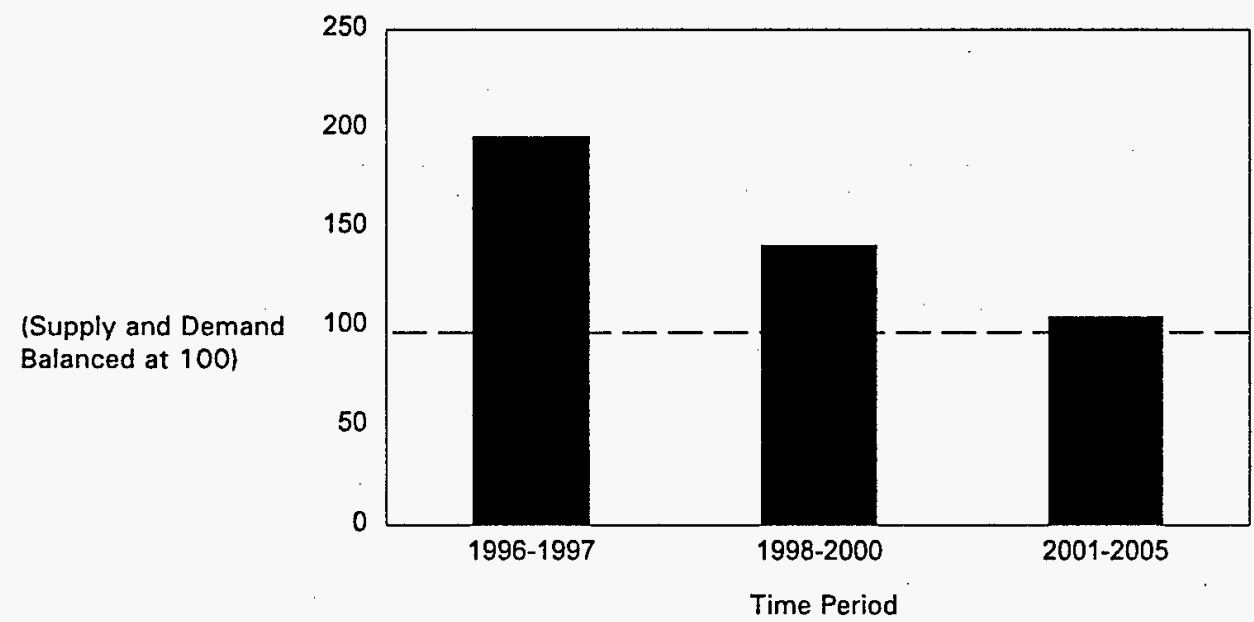

"Assumes the number of degrees and available supply of new graduates decline after 1997 proportional with recent decreases in enrollment trends. 
Discussions during the summer of 1996 with 20 university and college nuclear engineering programs indicate a continuation of an oversupply of new graduates and few job opportunities in the nuclear energy field. There were, however, a few signs of slightly more job openings in nuclear engineering than during 1994 and 1995 . The nuclear engineering academic programs reported a mixed situation in job searches and placements. In general, it appears that graduates are still experiencing difficulties in finding employment; this is particularly true for bachelor's degree graduates but also evident for master's and doctoral degree graduates as well. Compared to 1992, a larger number of schools indicate that there are fewer job opportunities in the nuclear field and less on-campus recruiting.

Despite these trends, however, there are no reports from university programs of widespread unemployment or of nonprofessional employment among the new graduates. A variety of factors appears to be positively impacting employment opportunities for the new graduates. A substantial number of graduates report obtaining employment as computer engineers or scientists, materials scientists, and mechanical engineers; they are also obtaining employment, to a lesser extent, in several other science and engineering fields based on the knowledge and skills acquired in their nuclear engineering education programs. Also, more nuclear engineers are acquiring education in radiation protection, and some are obtaining employment in the radiation protection field.

Some master's and doctoral degree graduates obtain employment using their skills in scientific computing and adapting basic research knowledge gained in nuclear engineering research to other fields such as petroleum research and atmospheric research. In addition, some master's and doctoral degree graduates are obtaining employment in Department of Energy laboratories and with the U.S. Nuclear Regulatory Commission. In comparison to the last couple of years, there appear to be a few more bachelor's degree graduates obtaining employment as nuclear engineers in nuclear electric utilities and still more obtaining employment in electric utilities in engineering fields other than nuclear. In addition, more bachelor's graduates are entering the U.S. military.

\section{Current Starting Salaries for Nuclear Engineers}

The rate of increase in starting salaries for new graduate nuclear engineers has slowed substantially over the past decade reflecting the relative change in labor market supply and demand conditions. Average annual increases of 5 to 6 percent were common in the 1980s, while over the last few years average annual increases have typically been in the 1 to 2 percent range. 9

Surveys of starting salaries and salary offers report that in the fall of 1995 the average starting salary for new bachelor's degree nuclear engineers in nuclear-related organizations was $\$ 36,600$, approximately 1.5 percent higher than in the prior year. This average salary, which includes nuclear electric utilities and non-utilities (excluding government and academic institutions) was slightly higher than for large engineering fields such as mechanical, civil, and electrical/electronic, but lower than for chemical engineers. (Figure 6.) The average bachelor's-level starting salary for nuclear engineers was the same as that for entry bachelor's degree health physicists (a nuclearrelated science specialty) but exceeded considerably the starting salaries for most other scientist occupations. ${ }^{10}$

In 1995, at the master's degree level, average starting salaries for new graduate nuclear engineers in nuclearrelated organizations was $\$ 39,000$, an increase of 2.1 percent over 1994 . The master's-level starting salary for nuclear engineers was slightly higher than that for health physicists, higher than starting salaries in scientist 
FIGURE 6. STARTING SALARIES FOR BACHELOR'S DEGREE GRADUATES, 1995

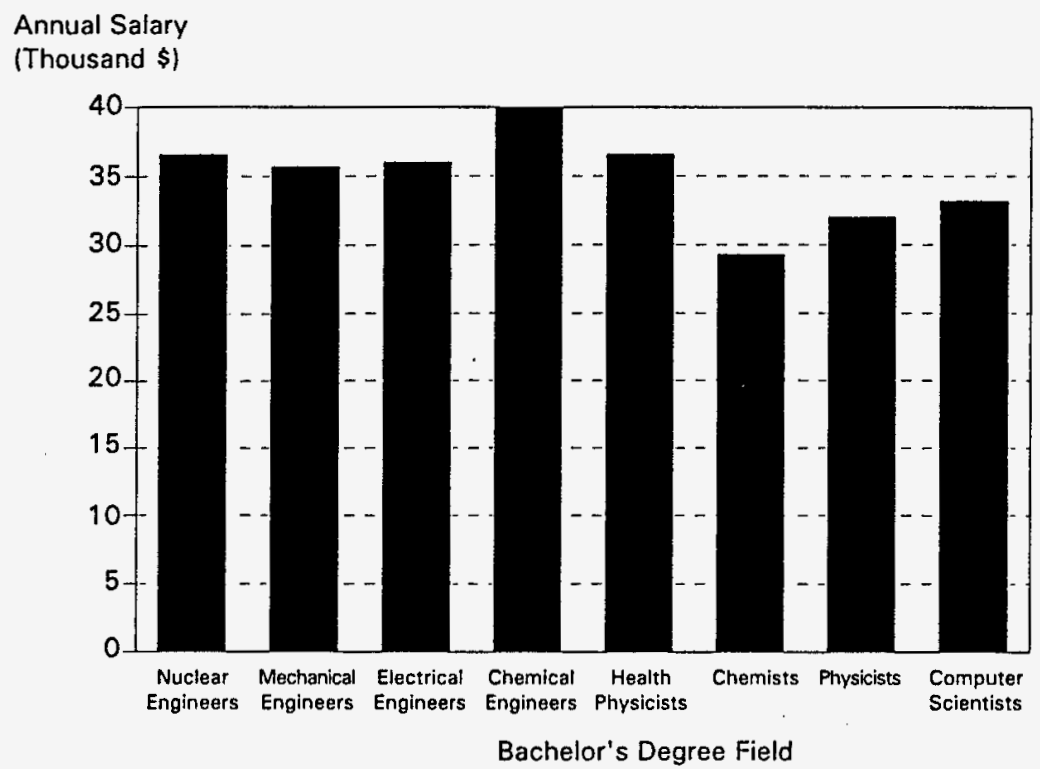

occupations (except computer scientists), but lower than starting salaries in large engineering fields. At the doctoral level, the average starting salary, excluding the nuclear electric utilities, was $\$ 47,500$, an increase of 2.0 percent over the prior year. ${ }^{11}$

Data on 1996 salaries for nuclear engineers indicate that starting salaries for new graduates working in nuclearrelated organizations are 2.1 percent higher than in 1995 for bachelor's degree personnel, 2.2 percent higher for master's degree personnel, and 2.9 percent higher for doctoral degree personnel. As in past years, the nuclear electric utilities have higher average salaries than non-utilities for bachelor's degree personnel while non-utilities have higher average salaries than utilities for master's and doctoral degree personnel. ${ }^{12}$

\section{LABOR MARKET OUTLOOK FOR NEW GRADUATES, 1998-2000}

\section{Trends in Employment and Job Openings}

For the period 1998-2000, nuclear engineering positions in the nuclear energy field are expected to decline by less than 200. This decline is almost entirely due to decreases in Department of Energy-funded activities of government, research and development, and waste management and environmental restoration. Some employment increases are expected in the nuclear defense segment. Fairly stable employment is expected in the nuclear electric utility industry. Based on discussions with employers, no further significant decreases in employment are expected in the reactor/facility design, manufacture, and redesign/betterment/backfit segment. Based on the expected employment trend, an estimated 250 to 300 annual job openings for new graduates are expected during 1998 through 2000 . Thus by 2000 , the expected annual number of job openings for new nuclear engineering graduates (all resulting from net replacement needs) is expected to be approximately 50 percent greater than the current number. 


\section{Enrollment and Degree Trends}

As noted earlier, the total number of nuclear engineering degrees declined by one-third between 1984 and 1992, and then increased by 11 percent from 1992 to 1995 . The increase was especially notable in master's degrees. In fact, the number of doctorates has been fairly stable since the early 1980 s varying between 97 and 135 degrees with no particular trends. The number of bachelor's degrees increased between 1992 and 1994, and then decreased substantially in 1995 .

Enrollment survey data (through the fall of 1995) reveal that total enrollments have declined 25 percent since the fall of 1992, with over half the decline occurring between 1994 and 1995. Discussions with university nuclear engineering programs indicate that this decrease in enrollments continued in the fall of 1996. These decreases in enrollments have occurred at all levels, but have been most pronounced at the undergraduate and master's levels, down 32 percent and 26 percent, respectively. In 1995, total enrollments were lower than at any time in the last fifteen years.

Based on these recent trends in enrollments, it appears likely that the number of degrees and the available supply of new graduates will decrease over the next several years. It will, however, take several years for the full effect of the declining enrollments to show up in the number of degrees. Thus, a decline of 10 to 15 percent in the annual number of degrees and available supply of new graduates may be a realistic expectation for 1998 through 2000 , resulting in about 375 to 390 new job seekers annually.

\section{Job Openings and Available Supply Outlook}

Assuming the increases in job openings in the nuclear energy field and the declines in available supply of new graduates as discussed provides a ratio of approximately 140 available new graduates per 100 job openings annually for new graduates during 1998 through 2000. While this is an improvement over 1996-1997, and a very large improvement over the 1990-1995 period, the ratio of available graduates to new jobs still indicates substantial oversupply of new graduates during the last three years of the decade.

If the number of degrees and available supply of new graduates remain at 1995 levels rather than declining in line with the recent decreases in enrollments, the oversupply of new graduates will be even larger (a ratio of 160 available new graduates per 100 jobs for new graduates). In order to balance the available supply and the number of expected new graduates (that is, obtain a ratio of approximately 100 available new graduates per 100 job openings for new graduates) during 1998 through 2000, the available supply would have to decline by one-third below recent levels.

In addition to large decreases in degrees and enrollments, other factors present in the labor market for nuclear engineers could help reduce the oversupply of new graduates. Recently, foreign nationals have earned about 15 to 20 percent of the total number of degrees granted and make up about 8 to 10 percent of the available supply of new graduates. If fewer foreign nationals remain in the U.S. labor force because of poorer job opportunities, then the available supply would be somewhat less. If declining job and career opportunities (real or perceived) in the nuclear engineering field increase the rate of career switches or retirements among those currently employed as 
nuclear engineers, attrition rates would increase as would the net job openings available for new graduates. Also, nuclear engineering job openings outside of the nuclear energy field provide alternative employment opportunities for the nuclear engineering graduates.

Other factors, however, may serve to increase the oversupply. In recent years, there has been an increase in the number of graduates entering the military and undertaking continuing studies (including those in postgraduate appointments). Initially, both of these postgraduation options decrease the available supply of new graduates; but, to the extent that these individuals complete their military commitments or continued studies and return to the civilian labor force seeking nuclear engineering positions, they will increase the available supply of job seekers. Also, as discussed, a large percentage of recent nuclear engineering graduates have accepted employment positions in nonnuclear engineering occupations. To the extent that these individuals continue to seek positions as nuclear engineers they will also increase the available supply of job seekers.

\section{LABOR MARKET OUTLOOK FOR NEW GRADUATES, 2001-2005}

\section{Employment and Education Trends}

From 2000 through 2005, the current outlook is for a slight increase in employment for nuclear engineers of approximately 150 positions. This employment outlook increases the expected number of annual job openings for new graduates to approximately 340 during the period.

As discussed, if the recent downward trends in enrollments continue through the rest of this decade and are reflected in decreases in the number of degrees, then a decrease in the number of available new graduates of 15 to 20 percent below the 1993-1995 levels might be expected. This provides an estimate of approximately 360 new graduates available annually for nuclear engineering civilian job openings.

\section{Job Openings and Available Supply Outlook}

Assuming these increases in job openings and the declines in available supply of new graduates provides a ratio of approximately 105 available new graduates per 100 job openings for new graduates annually during 2001-2005. Based on these projections, the labor market for new nuclear engineering graduates may be approaching a balance of supply and demand (or may even be balanced) after the turn in the century.

This balance reflects a decrease in annual numbers of degrees granted and available supply of new graduates of approximately 20 percent below 1995 levels and continued, somewhat higher-than-average for all engineering positions, attrition rates in nuclear engineering positions. Moreover, the cautions raised in the preceding section concerning other factors that can affect supply and demand trends must be kept in mind. In particular, if enrollments do not continue to decline and if the number of degrees and available supply of new graduates do not decline in line with decreases in enrollments, then a substantial oversupply of new graduates will continue to persist. Specifically, the current level of available supply of new graduates, provides a ratio of 125 available new graduates per 100 job openings for new graduates in the nuclear energy field. 


\section{ENDNOTES}

1. The nuclear energy field includes nuclear electric power operation, maintenance and servicing, vendors, the fuel cycle, decontamination and decommissioning, waste management and environmental restoration, research, government, university faculty, and nuclear defense activities. Excluded are medical facilities and active duty military.

2. Employment data are from the biennial Survey of Occupational Employment in Nuclear-Related Activities conducted by Oak Ridge Institute for Science and Education for the U.S. Department of Energy.

3. Enrollment and degree data are from the annual Survey of Nuclear Engineering Enrollments and Degrees conducted by Oak Ridge Institute for Science and Education for the U.S. Department of Energy.

4. The supply of new graduates available for U.S. civilian employment is defined as the number of new graduates minus the number who continue their studies, obtain a job outside the United States, or enter the active duty military.

5. U.S. Department of Labor, BLS, Office of Employment Projections, "Total and Net Occupational Separations: A Report of Recent Research," (Washington, D.C., 1991); and Michael G. Finn and Joe G. Baker, Phase I: A Comment on Occupational Separation and Replacement Needs for Engineers, (Oak Ridge, TN: ORISE, 1992).

6. "New Advice for the Graduate: Waning Industries," Wall Street Journal, p. B8, September 17, 1996; and discussions with faculty in academic nuclear engineering programs during the summer of 1996.

7. Data are from the 1993 National Survey of Recent College Graduates sponsored by the National Science Foundation, Science Resources Studies Division.

8. Data from the 1993 National Survey of Recent College Graduates and the 1993 National Survey of College Graduates sponsored by the National Science Foundation, Science Resources Studies Division.

9. Oak Ridge Institute for Science and Education, Salary Information for Nuclear Engineers and Health Physicists, various years, (Oak Ridge, TN).

10. Oak Ridge Institute for Science and Education, Salary Information for Nuclear Engineers and Health Physicists, October 1995, (Oak Ridge, TN, January 1996); and College Placement Council, Salary Survey, September 1995, (Bethlehem, PA, 1995).

11. Ibid.

12. Oak Ridge Institute for Science and Education, Salary Information for Nuclear Engineers and Health Physicists July 1996, (Oak Ridge, TN, October 1996). 
M97054487

|||||||||||||||||||||||||||||||||||||||||

Report Number (14) DOE/OR/00033--T776

Publ. Date (11) $\quad 199610$

Sponsor Code (18) DoE, NRC, XF

UC Category (19) uc-900,uc-000, DOE/ER

DOE 